\title{
A TERRA NA VISÃO INDÍGENA
}

\author{
The Earth on the Vision of Indigenous People
}

\author{
José Lino Menegassi
}

Professor Titular do Curso de Teologia da PUCPR, possui Mestrado em Ciências da Religião e

Doutorado em Direito das Relações Sociais, Curitiba - PR. e-mail: ejlmenegassi@yahoo.com.br

\section{Resumo}

Retratar a visão guarani da terra constitui-se em grande desafio. Na busca de fidelidade à compreensão indígena, metodologicamente, envereda-se pela exegese de textos de três vertentes: crônicas de descobertas e viagens, documentos missionários e literatura antropológica; além disso, conjugam-se a dimensão concreta, com descrições de cronistas e missionários sobre cultivos autóctones e sistema de distribuição com a dimensão interpretativa na qual se buscou entender a terra integrada no sistema simbólico indígena. No primeiro aspecto, constatou-se que, em situações normais, esse povo vivia em abundância, com alimentação variada, riqueza de animais, peixes e cultivo de roçados, atingindo, muitas vezes, além de cem anos de idade. Embora registros da presença de imperfeições terrenas no período pré-colonial, foi após os descobrimentos que se acentuou a deterioração cósmica que transformou muitos grupos em desterrados em sua terra de origem. No segundo aspecto, verificou-se que um tratado sobre a visão da terra na sociedade indígena, especificamente a guarani, não pode acontecer de forma isolada de seu universo compreensivo: a experiência terrena acontece cercada por um mundo místico, povoado de almas que irmanam todos os seres. A própria terra possui alma volúvel que reage conforme o tratamento que recebe e o ser humano tem responsabilidade sobre suas reações que podem resultar em tragédia ou apoteose.

Palavras-chave: Guarani; Terra; Reciprocidade; Animismo.

\begin{abstract}
To reflect about the Earth's Guarani vision becomes a great challenge. In the search for the fidelity to the Indians comprehension it was chosen the exegesis of texts from three sources: narratives about discoveries and travels, missionaries documents and anthropological literature; moreover, it relates the concrete dimension to chronists's and missionary's descriptions about autochthones cultivation's, and relates the distribution system to an interpretative dimension in which tried to understand the earth integrated into the indigenous symbolic system. On the first aspect it is showed that, in normal situations, this people lived in abundance, with variety of food, plenty of animals, fishes and gardens growing, being, many times, more than one hundred years old. Despite the register of the presence of earth's imperfection before the colonial age, it was after the discovering that the cosmic deterioration got accentuated, which transformed many groups in landless in its own native land. On the second aspect, it is clear that a work about the vision of the land in the indigenous society, specifically the guarani, can not be isolated from its all universe: the earth's experience occurs involved by a mystic atmosphere, crowed by souls that bind all beings. The earth, by itself, owns a soul that reacts to treatment received and the human being is responsible about its reaction that can result into tragedy or apotheosis.
\end{abstract}

Keywords: Guarani; Land; Earth; Reciprocity; Animism. 


\section{INTRODUÇÃO}

O desafio deste trabalho é apresentar com fidelidade a visão indígena da terra, tema impossível de ser tratado de forma global, por diversidade cultural dos povos autóctones, sendo que só no Brasil atual existem mais de duzentas formações culturais diferentes. Por isso opta-se por um dos povos indígenas sul-americanos que são os guaranis. A opção, no entanto, não é aleatória, seja pela importância que os guaranis tiveram na formação histórica americana, seja pela questão demográfica, ou pela devoção à terra típica desse grupo.

Mas, quem são os guaranis?

Dentre os povos não andinos da América do Sul, é o índio mais antigo que se perpetua até a atualidade. Desde Ramirez, em sua carta de 1528, até manchetes dos jornais dos dias de hoje, a presença desse povo é uma constante. É um povo profundamente ligado à formação histórica nacional como de todo o Paraguai, de significativas regiões da Argentina, como Corrientes e Misiones, do Brasil, especialmente Rio Grande do sul, Paraná, Santa Catarina e São Paulo, da Bolívia, sobretudo Santa Cruz de la Sierra e até do Uruguai.

Descendente direto do tronco tupi, que ocupava o litoral brasileiro à época dos descobrimentos, esse grupo formava províncias que abrangiam um território que se estendia desde a costa Atlântica ao Sul de São Vicente até a margem direita do Rio Paraguai e desde o sul do Rio Paranapanema e do Grande Pantanal, até as do Delta, junto a Buenos Aires. Sua população é estimada em cerca de um milhão e quinhentos mil a dois milhões de pessoas, tendo passado por intensa queda demográfica após a colonização.

Após a ocupação européia da América do Sul, províncias inteiras foram destruídas por guerras, maus-tratos, epidemias e cativeiro. Muitos foram absorvidos pela mestiçagem, outros reduzidos por Franciscanos desde 1580 e Jesuítas a partir de 1609. Alguns grupos conseguiram sobreviver livres, longe dos centros civilizados e, sendo raramente visitados, conservam seus hábitos até hoje. Estes constituem os Kaiguá, que se subdividem em Mbyá, Avá-Katú-Eté e Pai-Tavyterã.

Atualmente encontram-se guaranis, sobretudo em regiões da fronteira, no Paraguai, Argentina, Brasil e Bolívia. Apresentam índice demográfico relativamente elevado, sendo que os Pai-Tavyterã (ou Kayová) são uns dezessete mil, entre o Paraguai e o Brasil. Os Avá-Katú-Eté (ou Chiripá), são em torno de oito mil, também divididos entre o Paraguai e o Brasil. Os Mbyá são aproximadamente doze mil, distribuídos entre Argentina, Paraguai e Brasil. Por fim, os Chiriguanos que chegam a mais de sessenta mil e vivem na Bolívia e fronteira do Paraguai e Argentina.

\section{METODOLOGIA}

A metodologia adotada é a análise e interpretação bibliográfica. No entanto, a bibliografia sobre os guaranis, no seu estado atual, é enorme. Meliá (1987) indica nada menos que 1163 escritos catalogados. Diante dessa selva de papel, opta-se pelo modo de aproximação etno-histórico que, por sua intencionalidade, visa a compreensão da terra a partir da própria visão indígena. Nesta perspectiva, três são as fontes documentais pesquisadas: Crônicas de Descobertas e Viagens, Documentos Missionários e Literatura Antropológica, conforme explicitação seguinte.

\section{Crônicas de descobertas e viagens}

As primeiras notícias etnográficas sobre os guaranis apareceram com as expedições do Rio de La Plata e a conquista do Paraguai. O conquistador espanhol apresentou o guarani como eventual aliado político e social e, economicamente, como fornecedor de alimentos. Embora breves e esquemáticas, as notícias retrataram características fundamentais do modo de ser guarani, que pesquisas posteriores viriam confirmar. Da literatura espanhola deste período, a principal obra é a de Alvar Nuñez Cabeza de Vaca, que relataram a viagem da costa do Atlântico ao Paraguai, percorrendo dois mil e quatrocentos quilômetros, de Santa Catarina a Assunção, passando pelo Paraná. 
Do lado português, aparecem informações, sobretudo a respeito dos tupinambás, cujo tronco é o mesmo tupi, em cronistas como os franceses André Thevet e Jean de Léry.

\section{Documentos missionários}

Os missionários Franciscanos e Jesuítas conviveram intensamente com os guaranis no período colonial. Os documentos produzidos são marcados pela intenção de conversão dos indígenas. Embora a intenção comum, os documentos apresentam-se diversificados por características próprias de cada autor e pela destinação do escrito. Algumas vezes transparece admiração e entusiasmo. Outras, escândalo e indignação com o modo de ser e viver guarani.

Da literatura de origem espanhola, valendo-se com freqüência dos relatos reproduzidos nos Manuscritos da Coleção de Angelis, destaca-se principalmente o Padre Antonio Ruiz de Montoya que, ao lado da preocupação pastoral, demonstra autêntico interesse pela cosmologia indígena da época antiga. Outros documentos são da maior importância para o estudo da visão primitiva da terra. É o caso do Padre Martin Xavier Urtasún, que relata viagem de Assunção ao Paranapanema em 1612, e de um documento atribuído a um Jesuíta Anônimo, de 1620, sobre a fundação de Assunção. Por fim, Cartas Ânuas do Paraná e Uruguai de 1634, que retratam atitude fatalística do indígena frente à morte como despedida necessária da terra em que viviam.

Os documentos missionários são os mais importantes da literatura antiga sobre a compreensão da terra em sentido místico, pois o mundo religioso indígena, muitas vezes, representava o ponto de partida para conduzir os nativos à conversão.

\section{Literatura antropológica}

A seleção da literatura antropológica tem parâmetros bem determinados: autores que procuram falar a partir da experiência indígena. Pesquisadores cujo ponto de vista deixa de ser apenas o do homem civilizado para ser também e, sobretudo, o do índio.

O primeiro é Kurt Nimuendajú Unkel, autodidata alemão que veio ao Brasil no início do século passado e, convivendo com os apapocuva-guarani, tornou-se um marco para o conhecimento da cultura tribal, sendo inclusive rebatizado pelos indígenas, quando recebeu o nome de Nimuendajú.

No Paraguai coube a León Cadogan, autodidata como Nimuendajú, imprimir novos rumos à etnologia guarani. Ele dedicou muitos anos de sua vida aos mbyá, recolhendo grande cabedal de textos e ensinamentos míticos e religiosos. Foi um homem comprometido vitalmente com os destinos do guarani paraguaio. Discípulo dos sábios da comunidade, foi julgado digno de ser um daqueles que "sentam junto aos fogões", onde são transmitidos ensinamentos dos antepassados. Ele também recebeu seu nome indígena, que manteve em segredo até o final de sua vida: Tupã Kuxuví Vevé. Cadogan escutou a palavra guarani, estudou-a profundamente e com ela esculpiu sua forma de ser.

Schaden (1962) teve trajetória acadêmica. Professor da Universidade de São Paulo, uniu a atividade docente ao convívio com os apapocúvas de Araribá, onde ouviu pregações, participou de cantos e danças rituais e teve a experiência da amizade dos "paî", que eram seus informantes.

Por fim, Meliá (1987), jesuíta que desde 1954 dedicou-se ao estudo da língua guarani, sendo autor de fecunda produção intelectual. Discípulo e colaborador de León Cadogan, continuou sua obra no campo da pesquisa etnográfica e na defesa dos povos indígenas do Paraguai, Brasil, Argentina e Bolívia. É, entre os vivos, o que tem melhor conhecimento da cultura guarani.

O presente artigo articulará informações das três vertentes literárias, procurando detectar sua coerência sobre a compreensão da terra a partir de dois eixos que sustentarão a discussão: a reciprocidade e o animismo.

\section{A nova terra}

A forma de vida indígena integrada com a natureza encantou viajantes, religiosos, românticos e antropólogos ao longo da história. A abundância de riquezas, a solidariedade e a harmonia com o ambiente 
acompanham de forma quase unânime todas as narrativas. Em termos éticos, se para alguns pareceu necessária a mudança imediata de costumes, para outros, a liberdade e a fraternidade primitivas constituíamse em verdadeiros ideais de convivência pela possibilidade de expressão espontânea da vitalidade e sociabilidade humanas. Antropólogos contemporâneos, superando preconceito evolucionista, também não encobrem a admiração pelos valores de uma sociedade resguardada da corrupção da sociedade moderna que, muitas vezes, afronta a relação do homem consigo mesmo e com os outros, coaduna acumulação e miséria, bloqueia a percepção do sagrado, destrói a harmonia com o ambiente e agride toda a morada terrena.

Desde os relatos de Pedro Alvarez Cabral, forma-se generosa literatura sobre a saúde indígena, sua integração com a terra e toda a natureza. O escrivão da esquadra, Pêro Vaz de Caminha, retrata os silvícolas como gente parda, bem disposta, com cabelos compridos, que andava nua sem vergonha alguma, que trazia seu arco com flechas, como se estivesse ali para defender os rios. Tinham papagaios, cultivavam uma raiz chamada inhame que usavam como pão e arroz. Admira-se o escrivão da riqueza de árvores, águas, milho, algodão e da quantidade de peixes (VAZ DE CAMINHA, apud ARROYO, 1971). Não diferente é a impressão dos franceses André Thevet e Jean de Léry que estiveram em território brasileiro de 1555 a 1567, acompanhando Nicolau Durand de Villegagnon, que aqui queria fundar uma França Antártica. Thevet registra que os tupinambás se alimentavam de raízes e frutos e viviam longos anos, sãos e dispostos (THEVET, 1944). Léry conta que muitos chegavam até à idade de cento e vinte anos sem apresentar cabelos brancos (LERY, 1926). Sobre os guaranis Alvar Núñez Cabeza de Vaca, por meio de seu escrivão Pêro Hernandez, apresenta um quadro rico em detalhes, com especial destaque à economia. Para este político e aventureiro que foi de Santa Catarina a Assunção, numa distância de $2400 \mathrm{~km}$, atravessando o Paraná entre 1541 e 1545, para assumir o posto de governador da cidade paraguaia, o nativo era gente hospitaleira, que vivia em fartura, colhendo frutos das matas, cultivando lavouras e criando animais. Plantava milho e mandioca duas vezes ao ano, criava galinhas e patos e tinha em suas casas muitos papagaios (CABEZA DE VACA, 1971).

A forma de fazer as lavouras é descrita por um missionário Jesuíta numa Carta de 1620: primeiro derrubavam as pequenas árvores e depois as grandes; punham fogo no roçado e na terra fertilizada pelas cinzas, logo após o primeiro aguaceiro, plantavam mandioca e muitas outras raízes e legumes muito gostosos. E conclui que tudo produzia com grande abundância (JESUÍTA ANÔNIMO, apud MCA I, 1951). Outro missionário, Martin Xavier Urtasún, manifesta-se sobre a qualidade da alimentação e considera que as comidas indígenas, mandioca, batatas e vagens eram mais saudáveis e mais gostosas "que el pan regalado de Córdoba y que el carnero y demas guisados de los Coll...” (URTASÚN, apud MCA I, 1951).

Portanto, as primeiras notícias da plaga brasileira e de territórios da Argentina e Paraguai retratam uma terra de abundância, com alimentação variada, riqueza de animais e peixes, cultivo de roçados, convivência com animais domesticados, e indígenas vivendo, muitas vezes, mais de cem anos.

\section{A reciprocidade} com os visitantes.

Ao lado da produção, destaca-se a distribuição eqüitativa entre os componentes da aldeia e até

A generosidade e abundância era tanta que Cabeza de Vaca quando ia do Paraná em direção ao Paraguai, por exemplo, não podia permanecer em aldeia com sua tropa, pois os soldados caíam doentes de tanto comer. Mesmo assim, sobrava alimento para o caminho. Nas reduções do Guairá, os padres recebiam legumes, frutas e peixes que lhes sobrava para dar de esmolas a pobres e enfermos (MASTRILLO DURÁN apud MCA I, 1951).

Jean de Léry chamou essa cooperação econômica de caridade natural e virtude. Afirma ele que os tupinambás presenteavam-se diariamente com veações, peixes e frutas e que morreriam de vergonha se vissem o vizinho sofrer falta do que possuíssem (FERNANDES, 1963). Episódio comovente é reproduzido por Ives d'Evreux, em relato de sua viagem ao Norte do Brasil em 1613 e 1614. Narra o autor que um dia, numa aldeia chamada de Januarum, no atual Estado do Maranhão, só tinham farinha para

\section{$\overline{1 \text { Colégios. }}$}


comer. Apareceu, então, um rapaz que havia caçado uma perdiz; sua mãe depenou-a ao fogo, cozinhoua, deitou-a num pilão, reduziu-a a pó, e juntou-lhe folhas de mandioca, cujo gosto é semelhante ao da chicória selvagem, fez ferver tudo e depois de bem picado e cortado aos pedaços, desta mistura fez pequenos bolos, do tamanho de uma bala e mandou-os distribuir pela aldeia para cada choupana (D'EVREUX, apud FERNANDES, 1963).

Bartomeu Meliá sustenta que a generosidade que partilha tanto na abundância como nas privações ancora-se sobre uma economia de reciprocidade e qualifica como sendo de reciprocidade a economia na qual "o intercâmbio de bens, sejam de consumo ou de uso, é regido pelo princípio da distribuição igualitária segundo o qual a obrigação de dar supõe a obrigação de receber, e receber se torna uma obrigação de dar" (MELIÁ, 1989). A expressão econômica faz parte de um diálogo social e místico e o que circula é o prestígio de quem sabe dar e a alegria de quem sabe receber.

A reciprocidade se expressa do processo produtivo ao consumo, nas relações pessoais em amizade e vingança, nas infrações em punição proporcional. Essa mesma reciprocidade perpassa as relações com a terra.

Uma importante expressão de reciprocidade no processo produtivo é o "potyrõ". Se as lavouras têm certo caráter privado, sendo que cada família ou indivíduo pode ter o seu roçado, no "potyrõ" se estabelece uma relação de produção participativa, na qual conjugam-se trabalho e festa. Participar do trabalho e da festa gera obrigação de tornar-se também anfitrião.

Os europeus, desde o início, foram beneficiados e souberam explorar essa lógica indígena. Para cativar essa generosidade, Cabeza de Vaca oferecia aos guaranis presentes como facas, camisas e tesouras. Para o Jesuíta Anônimo, a fundação de Assunção deveu-se mais à sedução que à conquista. Julgando os índios tratarem-se os espanhóis de boa gente, ofereceram-lhes suas filhas e honrando-se com o novo parente acudiam a servir-lhes nas lavouras. Como recebiam comida em abundância e tinham muitas mulheres, nada mais aspiraram os espanhóis (JESUÍTA ANÔNIMO, apud MCA I, 1951). O mesmo Jesuíta descreve o domínio a que eram submetidos os guaranis. Para eles não restava terra, cavalo ou galinha. Calados, eram repartidos por espanhóis que desejavam seus trabalhos. Urtasún impressionouse com a fraqueza em que os encontrou em Maracayú em 1612. Por excesso de trabalho no corte da erva mate e falta de alimentação, estavam "flacos y en los huesos" (URTASÚN apud MCA I, 1951).

Outra face da reciprocidade é a vingança, tanto entre tribos como individualmente. O perdão não parece ser uma virtude guarani. Cabeza de Vaca diz que era gente muito amiga da guerra e que sempre a procuravam, por serem muito vingativos. Presos pelos inimigos, preferiam a morte a fugir, pela certeza de que seus amigos iriam vingá-los. Nas disputas pessoais, agarravam-se a paus e dentadas, não raro levando o adversário à morte. Mas as infrações às regras morais são punidas cósmica e socialmente com severidade e, muitas vezes, com penas equiparadas ao dano.

O castigo cósmico por infração moral é uma das constantes na religião indígena. Entre os guaranis aparece desde a mais antiga literatura. Tome-se como exemplo dois episódios narrados por Antonio Ruiz Montoya. No primeiro, conta o missionário que por causa do furto de cana de açúcar pelos vizinhos de uma plantação pertencente a um tal de Taubici, muitos foram castigados com a doença de câmaras, da qual alguns morreram. No segundo, já no ambiente cristão da redução de Caró, um rapaz foi caçar em um sábado de quaresma e fartou-se às escondidas e teve uma hedionda morte, a ponto de suscitar horror e escarmento na redução (MONTOYA, 1985). Se a proibição de caçar e comer carne em sábado de quaresma era uma implantação cristã, tanto o furto como a mesquinhez constituíam infrações também para os autóctones e seu castigo, imposição de seu direito consuetudinário, procedia tanto de forças sociais, como de poderosos seres espirituais.

Sobre a reciprocidade como punição paradigmática é a questão do homicídio. Quando alguém assassina seu conterrâneo, diz o cacique que exerce certa função de juiz, que neste caso há palavras: "calo-me impotente, faltam caminhos para minhas palavras (emudeço, não podendo alegar nada em defesa do assassino)" (CADOGAN, 1959). Quem assassinou, deve morrer. Aplica-se o princípio "ekovia va'erã teko avy" (teko avy $=$ desvio, ekovia $=$ dar em troca, substituir). Ou seja, dá-se a vida do assassino em compensação à da vítima. 
A mesma reciprocidade perpassa as relações com a terra. Ela é um ser vivo que reage conforme as atitudes humanas não só do presente como também do passado. $\mathrm{Na}$ terra, desde o nascimento, são encontradas sendas de imperfeição terrenas que resultam em infortúnios para seus filhos. A experiência do mal antecede inclusive o período colonial. A documentação histórica registra a existência de doenças e pestes e aponta como causa a proximidade dos rios e pântanos, como no caso de Assunção. Também padeciam os guaranis de fome, frio e "mil calamidades" (Cartas Ânuas de 1634, apud MCA IV, 1970). Essa experiência do mal fomentava migrações em busca de contextos mais saudáveis. Provocavam, também, danças e preces em busca de maior perfeição terrena.

A história colonial para o guarani é uma seqüência de males que não têm limites. Tornouse um desterrado em sua terra de origem. No entanto, em momento algum na antropologia guaranítica se encontra um indígena que se isente pessoalmente de responsabilidade. A imperfeição da terra é conseqüência sim da presença de invasores, mas, também, de infidelidade ao próprio "modo correto de ser", ensinado pelos grandes pais. O problema ecológico é um problema moral e reciprocamente as reações da terra e do cosmos são respostas às formas como se porta o humano em suas relações com a natureza.

Em todas as situações, as sendas de imperfeição têm aspecto moral: é ódio, avareza e feitiçaria. Mas, também, ecológica: a terra pode desmoronar por falta de suporte, incêndios devoradores avançam do Ocidente para o Oriente; em termos naturalísticos, são as secas prolongadas, esgotamento do solo, inundações, invasões de pragas e animais daninhos. Significa que na visão indígena, o mal na terra não é circunstância meramente moral ou ecológica, mas teko-lógica: o tekó porá, bom modo de ser, e o tekómarangatú, modo de ser religioso, deterioraram-se e transformaram-se em tekó-vaí, maldade, que pode destruir a terra. Nos cantos e danças rituais revelam-se quais são os males atuais que devem ser detidos com as rezas: montes desmatados, falta de religião dos brancos, fazendas que cortam caminhos, guerras, feitiçarias e homicídios. A conseqüência ecológica são ventos impetuosos, tempestades, incêndios, inundações, desgraças de todo o gênero, como mortes repentinas, enfermidades incuráveis, fome, suicídios e mal-estar social.

A sensibilidade para o mal na terra é destacada com tintas fortes pelos antropólogos modernos. O guarani já não tem para onde ir. Olhando-se tanto para o Oriente como para o Ocidente, o que se vê é a mesma devastação. A terra não explorada nem comercializada, idealizada pelo nativo, já não existe mais. A terra acolhedora, com frutas, aves, animais, rios e peixes, sucumbiu: toda a terra converteu-se em mal. Nimuendajú, que conviveu com os Apapocúva-Guarani modernos em Ariribá, diz que muitos já não acreditam em futuro algum, pois a terra está velha e já devorou muitos cadáveres, as águas querem descansar, estão exaustas as árvores e não querem mais fornecer lenha (NIMUENDAJÚ, 1987). Para muitos, a saída mística, com prolongadas danças que leva à exaustão, com cânticos pessoais e coletivos, expressaria simbolicamente a esperança de uma nova terra, sem, no entanto, manter sua força capaz de gerar migrações como acontecia primitivamente. Mas, enfim, a preservação e recuperação da terra acontecem simultaneamente ao resgate moral do ser humano.

\section{Almas que povoam a terra}

A primeira reação dos colonizadores frente aos indígenas americanos, em termos religiosos, foi de completa negação. Thevet (1944) afirmava que eles eram gente sem fé, lei, religião e civilização, Villegagnon, apud Prien (1985), afirmava que eles eram sem religião, virtude ou honradez e que não sabiam o que era justo ou injusto, enquanto que Montoya (1985) os consideravam feras e bárbaros. A falsa impressão encontra-se superada e hoje não se tem mais dúvidas de que os indígenas possuem sólida crença e sua compreensão da terra encontra-se integrada à visão cósmica e religiosa.

Genericamente, a religiosidade indígena, de forma semelhante à dos povos africanos, pode ser caracterizada como de um certo animismo. Em relação aos guaranis, a alma está presente em tudo. Assim, há a alma das rochas, das árvores, dos animais e dos seres humanos vivos e mortos. Mas há, também, a alma da terra. 
Sobre a dimensão anímica das rochas, há um episódio narrado por Montoya, ocorrido na redução de Candelária, onde três índios mantinham a crença de que nos penhascos havia uma força oculta que trazia boa sorte aos viajantes. Segundo o missionário, os três morreram após recorrerem aos rituais antigos, numa demonstração do caráter funesto dos costumes passados na visão missionária.

As árvores também possuem alma: algumas, alma indócil e que causam ferimentos; outras, benévolas e que servem aos homens. A mais rebelde entre todas é o lapacho, que, mesmo quando despedaçado, mantém seu espírito feroz, e por isso não deve ser utilizado para construção de vivendas. É o contrário do cedro, árvore de Namandú (sagrada). Esse sim deve ser utilizado em construções.

$\mathrm{Na}$ medicina, o poder das plantas encontra-se em sua alma e sua correta aplicação depende de iluminação dos grandes pais. Seus efeitos, da confiança do doente em sua eficácia. Ás vezes, parece que a alma se desprende da própria planta, evocando espíritos para auxílio do doente. Nesse caso, a planta é uma intermediária entre o doente e as almas que pairam sobre a natureza. A preocupação com a alma das plantas é transmitida às crianças por meio de brincadeiras. Em um dos seus cânticos, elas repetem: "Yvyra ñe'e ñand'api, ñand'api"; a alma da árvore nos fere, nos fere (CADOGAN, 1959).

A mesma alma está presente nos animais. Alguns têm alma má e trazem as doenças, como os veados e os sapos. Outros, periodicamente se comunicam com os grandes pais. É o caso de falcões e pombas. Há também os que anunciam infortúnios e enfermidades e os que transmitem mensagens dos mortos.

Além das almas de pedras, árvores e animais, existem almas espirituais que pairam sobre a natureza. São habitantes ociosos da terra, donos de precipícios e numerosos seres invisíveis que povoam todo o cosmos e afrontam o ser humano. Vivem vagando em busca de aventuras.

No âmbito tupi, teve grande importância o curupira, casta de seres sobrenaturais, gênios que se identificavam com a floresta. Eram bondosos e brincalhões, mas podiam tornar-se tirânicos e brutais e exigir oferendas dos caçadores.

Os guaranis-isosenhos do Chaco boliviano cultuam os kaá-ijá, donos da mata, aos quais pedem proteção e perdões pelo mal necessário que representa a morte do animal caçado.

Leon Cadogan traduziu uma expressão usada pelos guaranis, yvy re itáva reí va'e, por "habitantes ociosos da terra", entendendo-a como duendes e abrangendo numerosos seres, alguns relacionados com as florestas, outros com os animais e outros muitos com a alma humana.

Dentre esses duendes, encontram-se os iñakanguajá, donos dos barreiros, locais onde os animais vão em busca do sal que aflora na superfície da terra. Por vezes, manifestam-se em forma de meteoros. Então se diz: jopú iñakanguajá, os duendes estão de visita. Originariamente, Iñakanguajá foi homem virtuoso que havia alcançado a perfeição e estava próximo a chegar ao paraíso. Esse homem tinha acumulado muitos animais e construído uma casa muito grande. Ao chegar à terra da imortalidade, sua enorme casa na qual estavam ele e seus animais, enroscou-se na porta, impossibilitando a passagem. Por isso, ele com seus animais tiveram que permanecer na terra e converteram-se em espíritos protetores dos barreiros.

Outro habitante ocioso da terra é o Guachú ja Eté, o verdadeiro protetor dos veados. É também chamado de Onimbý e va'é, aquele que silva e atua na corrupção de donzelas. Também ele teve origem humana, tendo sido transformado por causa de uma infração moral. Conta-se que uma mulher entrou em uma chácara alheia para furtar frutas, levando consigo uma criança de peito. Como castigo, a criança foi transformada em Guachú já Eté e a mulher em veado.

Existem monstros que se confrontam com os humanos mesmo após à morte. Dentre eles, destacam-se o aña-karú (espírito antropófago), o guarudjê (morcego monstro), dos Kayovás de Dourados, ou o Pytu voy (casa das trevas), dos Kayovás do Alto Ypané, no Paraguai, ou o sapo kururú, da Aldeia de Jacaré́, no Mato Grosso do Sul.

Embora todo o cosmos seja povoado de almas e ele mesmo seja um ser animado, o ser humano, vivo ou falecido, ocupa lugar decisivo na constituição da harmonia ou caos no mundo simbólico guarani. Nele, vida e morte entrelaçam-se de forma inconsútil, sendo que a mesma alma que estabelece a comunicação entre os vivos mantém o diálogo com os mortos. Esse diálogo da alma que se expressava em economia de reciprocidade entre os vivos continua mediante várias formas de intercomunicação entre os vivos e os mortos. 
Montoya (1985) registra que desde o sepultamento, buscava-se proteger a alma do falecido. Por isso, enterrava-se em talhas grandes, sobre a qual se colocava um prato, para que ficasse acomodada. Quando o enterro era realizado conforme o costume cristão, portanto sem deixar-se qualquer concavidade na boca da sepultura, acudia de jeito muito dissimulado uma velhinha, munida de uma pequena peneira e procurava retirar a alma do falecido da cova para que não padecesse com o corpo (MONTOYA, 1985). Léry (1926) afirma que os tupinambás não só acreditavam na imortalidade da alma, mas que elas habitavam altas montanhas onde dançavam em belos jardins com as almas dos seus avós. As almas dos covardes, ao contrário, eram transformadas em Anhangá, que causavam grande temor pelos tormentos que podiam causar aos vivos. E os mortos mantinham freqüente comunicação com os vivos por meio de sonhos, da inspiração dos pajés e de certos animais, sobretudo de pássaros. O próprio Jean de Léry certa vez zombou de um grupo que escutava o canto noturno de um pássaro semelhante a uma pomba e recebeu a seguinte reprimenda de uma ancião: "Cala-te, e deixa-nos ouvir as boas notícias que os mortos nos mandam, pois nos faz contentes e nos dá novas forças” (LÉRY, 1926). Recentemente encontrou-se a prática de se fazer fogo sobre a sepultura em diversos grupos do Brasil cuja explicação por parte dos próprios guaranis é a de que o fogo serve para iluminar a alma do defunto que, após a morte, deseja percorrer todos os locais onde esteve durante a vida (SCHADEN, 1962). Permanece, também, o costume de colocarem-se os objetos do morto junto ao túmulo, sendo que quando esse era uma criança, acompanhava-a seus brinquedos e quando a mulher acompanhava-a a "porungá", que servia para carregar água. Quanto aos objetos de uso do morto, são colocados sobre a sepultura e, geralmente, abandonados. A exceção são as lavouras que podem ser colhidas.

Tanto na literatura histórica, seja de missionários ou de viajantes, como na moderna, a presença dos mortos que pode representar conforto e segurança ou temor e ameaça, conforme vinculação com diferentes dimensões anímicas, é uma das principais constantes. As dimensões anímicas que transformam o homem em um ser bifurcado, com tendências boas e más, separaram-se na morte, transformando-se em Ayvucué ou Anguéry, protetores de seus amigos ou perigosos fantasmas.

Algumas situações aumentam o temor dos fantasmas. É o caso da morte violenta e repentina. Então a alma perambula pelos lugares que andava em vida, especialmente à noite, constituindose em grave perigo aos viventes. Ou, a morte de um dos cônjuges, pois aí o finado pode voltar à noite para abraçar seu companheiro, o que significa morte certa. Quando se tem certeza de que Anguéry ou Anhangá está à solta, se alguém tiver coragem, deve procurá-lo para matá-lo. Senão, é preferível simplesmente abandonar o lugar.

Além da certeza da presença dos mortos expressa de forma mais ou menos teórica, existem ritos relacionados com os falecidos. Os que mais chamam a atenção são os que se vinculam à esperança de reencarnação dos próprios ossos. Sobretudo os Mbyás preservam com muito cuidado os ossos de seus familiares e temem que seus próprios sejam abandonados. Canta-se a morte como o afastamento e retorno ao céu do sopro vital, o que deprecia os ossos. Mas, embora aparentemente abandonados, eles serão mansamente iluminados pela luz benéfica dos relâmpagos, voltando novamente a circular a palavra que lhes dará nova vida. Há casos, inclusive, de conservação de ossos dentro da própria residência, enquanto se aguarda a nova vida.

A crença na vida dos ossos relaciona-se com uma outra forma de imortalidade muito comum na crença guarani: a vida perene pela perfeição pessoal. Nesta forma de imortalidade, ao contrário de outras escatologias na quais os homens são arremessados para o mundo dos deuses, passando a viver na atemporalidade, é o mundo dos deuses que é capturado por homens que atingem a perfeição e tornamse imortais. Funda-se uma escatologia terrena, muito bem ilustrada pela história de muitos pajés que, inclusive, passam a ser cultuados como verdadeiros deuses.

\section{A alma da terra}

O cosmos indígena é povoado de seres divinos, espirituais, naturais e sobrenaturais; não se encontra separado por um eixo vertical de um em cima e embaixo nem é formado por entidades tão autônomas como muitas vezes se pretende em catalogação etnográfica; tudo se resolve numa 
plataforma terrestre na qual o céu encontra-se na beirada, em direção ao leste. No presente, a terra é partícipe de um cenário vivo no qual uma constelação de seres irmanados dialoga de forma construtiva ou destrutiva e o desfecho dessa formidável peça depende de todos os seus atores, podendo resultar em apoteose ou tragédia.

A terra não é apenas palco, mas ator que responde às interpelações, se não exclusivamente pelo menos de forma determinante, às mensagens que lhe dirigem os humanos. Dela fazem parte os vegetais, como pele e pêlo de seu corpo, os animais que são seus protegidos e os seres humanos que se encontram na morada terrena.

Embora sendo um ser vivo que se corresponde com o ser humano, a terra não se constitui em divindade. Ela, da mesma forma que o homem, os animais, os mares e as árvores, foram concebidos e engendradas pelo grande pai, pela sabedoria de Nãmandu, "contida em sua própria divindade" (CADOGAN, 1959). Irmanados pela mesma origem, homem e terra permanecem num liame no qual a maldade de um reflete-se no outro e os caminhos da perfeição humana individual e coletiva têm como corolário a perfeição da própria terra. Unem-se numa teko-logia o humano e o ecológico que se expressa na busca da terra-sem-males, yvý marane'y, talvez a face mais conhecida da cultura guarani atualmente, até porque já foi tema de Campanha da Fraternidade da Conferência Nacional dos Bispos do Brasil. ${ }^{2}$

A busca de uma terra sem males motivou constantes migrações. Embora com conotação mística, desde informações mais antigas até as modernas, a terra ideal aparece como bem concreta: Montoya traduz a expressão yvý marane'y, por solo intacto e não edificado (MONTOYA, apud MELIÁ, 1989); essa terra da imortalidade é um local onde não imperam a doença e a morte, mas é, também, a superação da fome, da miséria e da pobreza econômica (SCHADEN, 1962).

Mitologicamente, a terra que se busca, às vezes, é retratada com profunda singeleza e sempre com alto grau de integração e harmonia entre os seres humanos e a natureza. No mito recolhido em Ariribá, por exemplo, na chegada ao paraíso, quem faz a anfitriã é Ñandecý, termo que significa o mais alto grau de perfeição feminina. No paraíso, há bananas amarelas e também mel para beber. Araras e sabiás conversam com os peregrinos que pedem cãnguijý, símbolo de festa. Nandecý fala: "Na terra a morte é o fim de vocês. Não voltem para lá, fiquem agora aqui” (NIMUENDAJÚ, 1987).

Se no presente a reconstituição da terra parece impossível, a utopia de uma terra de abundância e partilha continua viva e representa ânimo não sufocado pelas adversidades que de muito agridem esse povo. Além disso, ao lado da resistência que o mantém numeroso demograficamente, a coerência cosmológica sustenta-se desde os primeiros registros dos cronistas que aqui chegaram até os mais recentes trabalhos antropológicos. Em alguns casos, no entanto, a migração transita do telúrico para o metafísico, expressando-se em ritos religiosos. Mas sempre, seja na migração, na dança ou no cultivo, a vida da terra e na terra depende de um diálogo protagonizado pelo ser humano.

\section{CONSIDERAÇÕES FINAIS}

Para delinear a compreensão guarani da terra, tornou-se necessário conjugar duas dimensões: uma concreta, com descrições de cronistas e missionários sobre cultivos autóctones e sistema de distribuição; a segunda dimensão é interpretativa, na qual se buscou entender a terra integrada no sistema simbólico indígena.

No primeiro aspecto, constata-se que viviam em abundância, com alimentação variada, riqueza de animais e peixes, cultivo de roçados, convivência com animais domesticados, atingindo, muitas vezes, mais de cem anos de idade. Embora registros da presença de imperfeições terrenas no período précolonial, foi após os descobrimentos que se acentuou a deterioração cósmica que transformou muitos grupos em desterrados em sua terra de origem.

2 Campanha da fraternidade de 2002. 
No segundo, verificou-se que um tratado sobre a visão da terra na sociedade indígena, especificamente a guarani, não pode acontecer de forma isolada de seu universo compreensivo: a experiência terrena acontece cercada por um mundo místico, povoado de almas que irmanam todos os seres. A própria terra possui alma volúvel que reage conforme o tratamento que recebe principalmente do ser humano. Em conseqüência, o ser humano tem responsabilidade sobre as reações da própria terra que podem resultar em tragédia ou apoteose.

\section{REFERÊNCIAS}

ARROYO, L. A carta de Pêro Vaz de Caminha: ensaio de informações à procura de costumes válidas de método. São Paulo: Melhoramentos, 1971. A carta de Pêro Vaz de Caminha é um relato a D. Manuel, sobre o descobrimento do Brasil em 1500.

CABEZA DE VACA, A. N. Naufrágios y comentários, com dos cartas y relación de Hernado de Ribeira. 5. ed. Madrid: Espasa calpe, 1971. A primeira edição da obra de Cabeza de Vaca é de 1555.

CADOGAN, L. A. R. Textos míticos de los Mbyá-Guairá. Boletim, n. 227 da Faculdade de Filosofia, Ciências e Letras da Universidade de São Paulo. Antropologia, São Paulo: n. 5, 1959.

Cartas Ânuas das Reduções do Paraná e Uruguai de 1634. Santos Mártires de Caro, 21-IV-1635. In: MCA IV. 1970. p. 80-144.

FERNANDES, F. Organização social dos Tupinambás. São Paulo: Difusão Européia do Livro, 1963.

JESUÍTA ANÔNIMO. Informe sobre as cidades do Paraguai e do Guairá. Espanhóis, índios e mestiços. Dezembro de In: MCA I, 1951. p. 163-173.

LÉRY, J. História de uma viagem feita à terra do Brasil. Tradução ordenada literariamente por Monteiro Lobato. São Paulo/Rio de Janeiro: Companhia Nacional, 1926. A principal edição desta obra é de 1580 .

MCA I. Manuscritos da Coleção de Angelis, I: Jesuítas e bandeirantes no Guairá (1540-1640). Introdução, notas e glossário por Jaime Cortesão. Rio de Janeiro: Biblioteca nacional, 1951.

MCA IV. Manuscrito da Coleção de Angelis, IV: Jesuítas e bandeirantes no Uruguai (1611-1758). Introdução, notas e sumário de Hélio Vianna. Rio de Janeiro: Biblioteca Nacional, 1970.

MASTRILLO DURÁN, N. Carta Ânua em que dá conta do estado das reduções da Província do Paraguai durante os anos de 1626-1627, na parte que diz respeito às reduções do Guairá, Cordova, 12 de novembro de 1628. In: MCA I. 1951. p. 203-258.

MELIÁ, B. A experiência religiosa guarani. In: MARZAL, Manuel. O rosto índio de Deus. Tradução de Jaime a Clasen. Petrópolis: Vozes, p. 1989. p. 293-346.

MELIÁ, B; SAUL, M. V.; MURARO, V. F. O guarani: uma bibliografia etnológica. Apresentação de Egon Schaden. Santo Ângelo: FUNDAMES, Centro de Cultura Missioneira, 1987.

MONTOYA, A. R. Conquista espiritual feita pelos religiosos da companhia de Jesus nas províncias do Paraguai, Paraná, Uruguai e Tape. Tradução vernácula: Arnaldo Bruxel. Porto Alegre: Martins, 1985. A primeira edição desta obra é de 1639. 
NIMUENDAJÚ UNKEL, C. As lendas da criação e destruição do mundo como fundamentos da religião dos Apapocúva-Guarani. São Paulo: HUCITEC; EDUSP, 1987.

PRIEN, H.-J. La história del cristianismo en america Latina. Salamanca: Sinodal, 1985.

SCHADEN, E. Aspéctos fundamentais da cultura guarani. São Paulo: Difusão Européia do Livro, 1962.

THEVET, A. Singularidades da frança Antarctica a que outros chamam de américa. São Paulo: Companhia Nacional, 1944. A primeira edição desta obra apareceu em Paris, no ano de 1561.

URTASÚN, M. X. Carta relatando a viagem desde Asunción às reduções do Paranapanema. Pueblo de S. Ignacio, 6-VII-1612. In: MCA I, p. 144-148.

Recebido em: 20/07/2006

Received in: 07/20/2006

Aprovado em: 30/09/2006

Accepted in: 09/30/2006 